\title{
Debate \\ The Right To Die Lives! There IS no Personhood Paradox
}

\author{
JOHN HARRIS*
}

\section{INTRODUCTION}

In an interesting and sophisticated paper Mary Ford attempts to find a paradox and a number of contradictions in personhood theory which bear on the question of the right to die. Her paper, 'The Personhood Paradox and the Right to Die', ${ }^{1}$ devotes a large part of its content to developing a philosophically rich account of various notions of personhood from Kant and Locke to some contemporary personhood theorists such as Derek Parfit, Mary Ann Warren and Peter Singer. All this leads up to the identification of so called contradictions and paradoxes which are supposedly relevant to contemporary life and death decisions such as that in the case of Dianne Pretty. ${ }^{2}$ I am afraid it is at this point that the paper fails to be convincing. I suggest that there is no paradox, no contradictions and it is important for any alleged right to die to be clear about why this is.

\section{THE ALLEGED PARADOX}

Ford sets out her stall thus:

According to personhood theory itself, anyone who still possesses the qualities of rationality, autonomy and self-awareness is unequivocally 'a person'; to suggest otherwise would constitute what Warren would term a 'personhood plus' position-a departure from the thesis that possession of the 'personhood-relevant

\footnotetext{
* Sir David Alliance Professor of Bioethics, Centre for Social Ethics and Policy, School of Law, University of Manchester (John.Harris@manchester.ac.uk). The author acknowledge the stimulus and support of the European Project on Delimiting the Research Concept and the Research Activities (EU-RECA), sponsored by the European Commission, DG-Research, as part of the Science and Society Research Programme: 6th Framework, in the preparation of this paper.

1 M. Ford, 'The Personhood Paradox and the Right to Die' (2005) 1 Med. L. Rev. 80-101.

2 Pretty v. United Kingdom [2002] 2 F.L.R. 45.
} 
properties' alone is sufficient to endow an entity with ultimate value. Accordingly, then, personhood proponents are obliged to recognise the ultimate moral value of the entity in the situation described above. Is that entity's wish to exercise a 'right' that will cause her death a reasonable position? More specifically, is the right claimed a morally-defensible one? On the face of it, it would seem that an entity which is rational, autonomous and self-aware is unreasonable in wishing for its own demise, since (according to personhood theory at least) in wishing for this it is wishing for the destruction of something of ultimate value. It would appear objectively-unreasonable, then, that anyone who could reasonably be considered a 'locus of rights' would wish to die, and to claim that such a desire could be the subject of a 'right' would appear equally unreasonable, since such a 'right' is incapable of moral justification.

Nevertheless, some personhood theorists do talk of a 'right to die', apparently without perceiving any incoherence or contradiction in the juxtaposition of the rationality and autonomy inherent in the very notion of a 'right' with the idea of a 'life not worth living'.

Ford has a very simple view of the relationship between personhood and ultimate value. She seems to think, without arguing for it, that 'ultimate value' is necessarily 'inalienable value' and that the things or considerations, which establish that a being has ultimate value are quite unconnected with the way that value is to be understood and analysed. Ultimate value is treated by Ford as entailing that beings of ultimate value may not be destroyed under any circumstances, to do so would she believes negate the value that they have. Moreover 'a rational, autonomous and self aware' individual is unreasonable to wish for the destruction of something of ultimate value. Whether or not this is so depends on how that value is to be established and understood. In short it depends upon what it means to have ultimate value. Ford just assumes that 'ultimate' means 'must be preserved at all costs'. But does it, and more importantly is there anything in personhood theory that requires that it does? We will examine these claims further in the light of the support that Ford adduces for them.

Ford claims that ' $[\mathrm{t}]$ he first contradiction can be summarised as follows: can we say that if a being possesses criteria $x, y$, and $z$, it is of ultimate value and deserves the utmost protection, yet simultaneously claim that we ought not to interfere if such a being wishes to destroy itself?" Ford believes the answer to this rhetorical question is 'no'.

3 Supra, n. 1 at p. 94.

4 Supra, n. 1 at p. 95. 
She goes on to claim that this is a pitfall and that voluntary euthanasia cannot avoid this pitfall. However, one problem for Ford is that this is not the only way of avoiding the problem. ${ }^{5}$ Ford assumes, on no basis whatsoever, that ultimate value, or moral status, equates to inviolability or equates to an obligation to persons to preserve their lives at all costs. Ford's account treats persons as if they were things and the obligation to them is not an obligation to a 'thinking intelligent being which has reason and reflection' ${ }^{6}$ but simply to an instance of ultimate value. Ford treats the value of life as an inalienable right but offers no arguments as to why this must be so.

Both of these interpretations of personhood would require some argument and do not seem obviously to flow from any of the accounts that the author considers. The Kantian account, in making autonomy central to personhood for example, might most reasonably be interpreted as requiring that it is autonomy that is protected not physical life. If it is autonomy that makes for ultimate value then the contradiction is in treating the value as unrelated to autonomy. The wishes of the autonomous individual are obviously relevant to the account to be given of what respect for personhood or respect for the value of the life of a person would amount to.

At this point I have to declare an interest in the debate. My own account of personhood ${ }^{7}$ demonstrates exactly why personhood does not have the problems Ford thinks she sees and precisely why this is so. My account identifies the criterion for personhood as that set of capacities that make it possible for a creature to value its own existence. On this account, a person is a creature capable of valuing its own existence and the wrong of killing or ending the life of a person is the wrong of depriving that individual of something that they value, namely existence. On my account of personhood, it is obvious that the paradox identified by Ford cannot arise, since if an individual does not value existence (or cannot value it) they are not wronged by being deprived of it and hence the ethics of end of life decisions are fully accounted for within the concept of personhood employed.

Ford identifies a second supposed contradiction which she characterises as 'the erroneous assumption of the conceptual separability of a

5 Ford believes that the only way of circumventing this paradox is to suggest that a being of ultimate value ought to have complete freedom to determine the parameters of his or her own existence and suggests that this must also fail for reasons which, while weak, have some plausibility. However the task of showing why these reasons are also beside the point will take too much space here.

6 J. Locke, An Essay Concerning Human Understanding (Oxford University Press 1964) Bk. II, Ch. 27.

7 Developed inter alia in John Harris, Violence and Responsibility (Routledge and Kegan Paul 1980) and John Harris, The Value of Life (Routledge and Kegan Paul 1985). 
subject and his or her life'. ${ }^{8}$ I do not believe that any of the accounts of personhood surveyed by Ford exhibit this defect or make this assumption. It is true that Dianne Pretty and others demonstrate their personhood by articulating their wish to die since, as my account briefly summarised above points out, the very same set of capacities required for valuing existence are also required for disvaluing it. But the alleged false dichotomy is in fact part of Ford's conceptual apparatus not that of the personhood theorists she criticises. She has failed to recognise that it is not life that is being valued, it is existence of a particular sort. Indeed, on many accounts of personhood, including that of myself, Singer and others, persons need not be organic life forms at all. It would be possible for very sophisticated computers which are not alive in any sense to be persons, and the wrong of ending their existence would be the same as the wrong of ending the life of an organic person but not because they were alive. Persons are the set of capacities that make for personhood, however embodied or individuated and the value of the existence of persons has to be understood in terms of the nature of those capacities. In short, it is Ford that displays the unacceptable dualism, supposing as she does that the ultimate value of life is separable from the personhood-establishing properties of the individual whose life it is. Whether embodied in an organic life form or in a constructed mechanical/electrical device (or even, as Fred Hoyle in his brilliant book The Black Cloud ${ }^{9}$ imagined, as a self-conscious cloud of gas), persons are valuable because they have the capacity to value their own existence. The nature of the value thus embodied has to be understood in terms of the sort of existence that is the existence of persons with the interests and preferences persons uniquely have in virtue of their personhood and the rights that under some theories these preferences and interests create.

Ford's last point about whether or not personhood is a matter of degree or a threshold concept seems confused. Most personhood theorists, I think, treat personhood as a threshold. The author does not sustain the claim that threshold approaches to personhood are inevitably arbitrary, not least because the capacities required for crossing the threshold are usually separately and carefully argued for. On personhood theory the value of life can be taken to be the value of personhood and therefore the value of the life separable from the personhood is zero. Most personhood theorists think that once personhood has disappeared (as in permanent vegetative state) or before it has arisen (as with the fetus and embryo), the life has no value; it is the personhood that is

\footnotetext{
8 Supra, n. 1 at p.94.

9 F. Hoyle, The Black Cloud (Penguin 1971).
} 
valuable, embodied, in the case of humans, in an organic living body but in the case of other possible forms which persons might take, not necessarily so embodied.

Once we see that this is an issue of interests we can ask the question: what interest does this person have in continued existence? And if the answer is 'none', then their interest in living, or their right to life cannot be violated. ${ }^{10}$ Since these interests can include an interest in ceasing to exist, there is nothing paradoxical or inconsistent in recognising that it can be in the interests of a person to die and hence that killing can constitute respecting the personhood of individuals. In short, persons are creatures the value of whose existence is constituted by their interests and preferences. To think of the value of life as simply the value of maintaining an organic life form which happens to be the life form of a person is simply to misunderstand what is being talked about when we talk about the value of the life of persons.

When Ford says 'on a personhood only account of moral status, Dianne Pretty qualified as a person', ${ }^{11}$ this is right so far as it goes. Dianne Pretty had a valuable life when she made her preferences about ending her life known. But the author fails to analyse what it means to have a valuable live in the sense in which personhood theorists use the term. The subject of a valuable life has an existence in which the interests of the person whose life it is count. In Bentham's famous terminology 'everybody to count for one, nobody for more than one'. ${ }^{12}$ But counting for one does not simply mean that sustaining life is what is required by recognising that an individual's life counts.

Recently I tried to express this idea in terms of human dignity. In a paper written with John Sulston about the requirements of justice when applied to genetics, we suggested:

Grounding genetic equity in the idea of the equal standing of each person, the idea that each is entitled to the same concern, respect and protection as is accorded to any; in Bentham's formulation of the idea, that each is to count for one and none for more than one, we have a clearer picture both of what constitutes human dignity and what derogates from it. This picture moreover is instructive, action guiding in the sense that all moral principles must be. Human dignity is on this view expressed in terms of equal standing in the human community and in equal respect for

${ }^{10}$ Although the person who is then killed remains a person with a valuable life its value being recognised as the set of interests that the characteristics of personhood make possible and which death fulfils.

11 Supra, n. 1 at p. 95.

12 See J.S. Mill in M. Warnock (ed.) Utilitarianism at 319 (Collins/Fontana 1962). See also J. Harris and J. Sulston 'Genetic Equity' (2004) 5 Nature Reviews Genetics 796. 
rights and interests. Bentham's phrase is, we believe, tellingly apposite, containing as it does two ideas. The first is the idea of counting equally-numerical counting. If one person counts for one then two count for two and so on. This idea shows us why we always have a moral reason to save more lives rather than fewer, because each life matters equally. Bentham's second idea contains the thought that people not only matter numerically, count for one, but that they also count in a more absolute and existential sense-they count for something! In short they matter, they count because they have equal dignity and standing. ${ }^{13}$

On this view, equal standing in the human community is what is meant by ultimate value. It is what personhood theory tries to explain. But personhood is also an explanation of what it means to count for something. The value of life is the ultimate value possessed by everyone who counts equally as possessing ultimate value but this value has content beyond simple existence. To count for something asks (but does not beg) the question: to count for what? The answer to this question is, on my account of personhood, that persons count for something because persons are the sorts of creatures who are aware not only that their existence matters to themselves, but because they have a view about both why and indeed whether or not it matters that existence continues. ${ }^{14}$

An importantly related idea is outlined by Ronald Dworkin in Life's Dominion. ${ }^{15}$ Dworkin is not a personhood theorist but his account of the ultimate value of life is consistent with personhood and inconsistent with Mary Ford's view of what the value of life must mean:

The great moral issues of abortion and euthanasia, which bracket life in earnest, have similar structure. Each involves decisions not just about the rights and interests of particular people, but about the intrinsic, cosmic importance of human life. In each case, opinions divide not because some people have contempt for values that others cherish, but, on the contrary, because the values in question are at the centre of everyone's lives, and no one can treat them as trivial enough to accept other people's orders about what they mean. Making someone die in a way that others approve, but he believes a horrifying contradiction of his life, is a devastating, odious form of tyranny. ${ }^{16}$

\footnotetext{
${ }^{13} \mathrm{Ibid}$. at p. 800.

${ }^{14}$ See John Harris, Violence \& Responsibility, supra, n. 7, ch. 1 and John Harris, The Value of Life, supra, n. 7, ch. 1.

${ }^{15}$ R. Dworkin, Life's Dominion (HarperCollins 1993).

${ }^{16}$ Ibid. at p. 217.
} 
Dworkin is insisting that the meaning of 'the intrinsic, cosmic importance of human life', what Ford calls 'ultimate value', has meaning. That meaning, whatever it is, (and Dworkin has a very complex and sophisticated account to give of this ${ }^{17}$ ) is how the ultimate value of life must be understood. It cannot simply be stipulated to be the same as an inalienable right to life or as Ford seems to suggest an unqualifiable obligation to preserve lives which have ultimate value. If Ford is right, not only personhood theorists are in trouble, but also those, like Dworkin, who understand the moral importance of life in terms of the nature of the capacities and interests that make life important to the individual whose life it is.

We cannot give an account of what it is to respect the value of a life unless we can say what those interests are, what it is that makes the life count for something or count for nothing. Personhood theorists can, and most do, hold that the value of a life, its ultimate value, consists in respect for the value that the individual whose life it is places upon continued existence. Ultimate value properly understood is not inalienable or immutable. Its ultimate nature consists in the claim that only the subject of lives of this sort can determine whether or not continued existence is compatible with the value of their life. If you like, persons are the sorts of beings that have a right to have the value of their lives respected but they are not doomed to have it respected. They can waive their right. Or, if the analysis of personhood is in terms of interests, they are the sort of beings who have an interest in continued existence, but that interest may sometimes be a negative rather than a positive interest, an interest in not continuing to exist. If the most significant interest is that life will end when the person whose life it is wants it to then there is no paradox—end of story! ${ }^{18}$

${ }^{17}$ Ibid. For a discussion of Dworkin's account in the context of euthanasia see J. Harris, 'Euthanasia and the Value of Life' in J. Keown (ed.), Euthanasia Examined: Ethical Clinical and Legal Perspectives (Cambridge University Press 1995) pp. 6-22.

18 And end of life! 